Gavurova, B., Ivankova, V., Rigelsky, M., \& Kmecova, I. (2020). How Do Gender Inequalities in Health Relate to the Competitiveness of Developed Countries? An Empirical Study. Journal of Competitiveness, 12(3), 99-118. https://doi.org/10.7441/joc.2020.03.06

\title{
HOW DO GENDER INEQUALITIES IN HEALTH RELATE TO THE COMPETITIVENESS OF DEVELOPED COUNTRIES? AN EMPIRICAL STUDY
}

\author{
- Beata Gavurova, Viera Ivankova, Martin Rigelsky, Iveta Kmecova
}

\begin{abstract}
Public health plays an important role in the spectrum of economic indicators. Simultaneously, the competitiveness of countries is a key economic indicator, and this interconnection requires special attention, especially in the decision-making process of public policies. The main objective of the presented study was to evaluate the effects of selected health indicators on the competitiveness of developed countries. The following health variables were collected for the analysed period from 2010 to 2018: four variables of Life Expectancy (LE) and three variables of Perceived Health Status (PHS). Each variable was observed from the perspective of gender differentiation and gender inequalities. The Global Competitiveness Index (GCI) was also used in the analyses as an economic variable. The research sample included all countries of the Organisation for Economic Co-operation and Development (OECD). The analytical data processing consisted of descriptive analysis, difference analysis (Wilcoxon Test), regression analysis (Panel regression model) and correlation analysis (Spearman's @). Regarding the results, all health variables showed differences between men and women. The results of the regression analysis revealed a very strong and significant effect of LE and PHS on the competitiveness of individual economies. The correlation analysis confirmed all relations. Improving the health of men and women is likely to increase the competitiveness of developed countries. As a result, it provides space for further research and policy-making in each country.
\end{abstract}

Keywords: Competitiveness, Global Competitiveness Index, Health Inequalities, Life Expectancy, Perceived Health Status, Gender

JEL Classification: I14, 047

Received: March, 2020

1st Revision: August, 2020

Accepted: August, 2020

\section{INTRODUCTION}

In economic theory, it is proclaimed that good health is very important in supporting the economic situation of countries. Many research findings have confirmed a positive impact of health on various aspects of economic life in countries, including productivity, income, consumption, as well as economic growth (Bloom et al., 2004; French, 2012; Herzer \& Nagel, 2019; Kalemli- 
Ozcan et al., 2000; Sharma, 2018; Weil, 2007). However, the question of whether there is an explicit relation between the health of the population and the competitiveness of countries remains open.

The health status of the population varies considerably from country to country and within each of them, while differences in health are evident in terms of geographical aspects as well as in terms of gender differentiation (Birader \& Öztüren, 2019; Štefko et al. 2020). On the other hand, there is a lack of research activities examining health inequalities and their effect on the competitiveness of countries. For this reason, research that fills this gap is necessary and beneficial, as health and competitiveness are considered to be key aspects of a country's economic life. Based on this, the main objective of the presented study was to evaluate the effects of selected health indicators on the competitiveness of developed countries. In other words, the study verified the assumption about the existence and nature of the economic effects of health indicators and gender health inequalities on global competitiveness. The research included analytical procedures to achieve this objective, namely a descriptive analysis, an analysis of differences between men and women in life expectancy and perceived health status, and a regression analysis that examined the effects of these health indicators on the competitiveness of OECD countries. At its procedural and result level, the presented research study offers a new perspective on the population's health as a key factor in the country's competitiveness.

The structure of the study is as follows: the theoretical background provides an overview of international studies dealing with research in the examined issue, while their main findings were used to create the analytical framework and to determine the main research trajectories. In the methodology section, the study specifies the fundamental methodological procedures and describes the variables used in the research. The next section consists of the analytical methods used to examine predetermined research trajectories. This section also interprets the results of the analyses in order to create a wider framework for discussion. Finally, the main findings are summarized and the research platform for future research in this area is formed.

\section{THEORETICAL BACKGROUND}

Public health is currently one of the most discussed social topics in the world, policy makers seek to understand health from different perspectives, while the economic perspective of health has an irreplaceable place in decision-making processes (Nemec et al., 2020; Šumpíková \& Durčeková, 2019). From a macroeconomic point of view, the health of the population is of great importance, as it is a source of economic and social development and the effects of health on various areas of life are considerable. For these reasons, improving the health of the population and reducing health inequalities should be one of the main strategic objectives of any country (OECD, 2019; WHO, 2013). On the contrary, the poor health of the population can weaken the economic condition of countries.

In recent years, many international research studies have examined the effect of health on economic processes at both macroeconomic and microeconomic level. For instance, the study conducted by Monterubbianesi et al. (2017) revealed that healthier population brings greater economic benefits in terms of increased productivity and long-term income of countries. In 
the studies of Khan et al. (2016) and Li \& Huang (2009), it was proved that a co-integration connection between health and education has positive effects on the economic growth. The effect of the health status of the population can also be found in other economic and social aspects, such as countries' innovation performance (Herzer, 2020; Pacáková \& Kopecká, 2019), knowledge transfer (Bar \& Leukhina, 2010), technological progress (Gehringer \& Prettner, 2019; Lechman, 2019), labour supply (Jiang et al., 2019), and poverty (Kim, 2018; Rakauskienè \& Volodzkiené, 2017).

These facts prove that health has an effect on various areas of economic life in countries. Also, Madsen (2016) and Mihalache (2019) emphasized the importance of healthy human capital in economic terms, while both believe that economic growth is represented by population health. Healthy human capital has a significant effect on the growth of the manufacturing sector in countries (Hena et al., 2019), which emphasizes a productive contribution to the economic performance of countries (Bloom \& Canning, 2003).

Regarding the health outcomes, life expectancy is a health indicator which is very frequently used. In the study conducted by Onsel et al. (2008), the relation between this indicator and competitiveness is evident. The authors consider life expectancy to be the fourth most important criterion of the countries' competitiveness, especially of those with a low level of competitiveness (factor-driven economies). The following countries are the examples provided by the authors: Croatia, Mexico, Poland, and Romania. Also, Salahodjaev \& Nazarov (2013) revealed that an increase in life expectancy increases the competitiveness of human capital, as well as the position of developing countries in assessing their competitiveness represented by the GCI index. The GCI index represents a commonly used tool which identifies a sustainable economic development of the countries (Lall, 2001). Bucher (2018) revealed its high correlation with human development index (HDI), gross domestic product (GDP) and the level of gender inequality.

Gender inequalities represent a serious element that can affect economic life in countries, as well as their competitiveness. Kroupova \& Rezankova (2016) confirmed a moderate positive correlation between gender gap index (GGI) representing the gender inequalities in four main areas (economic participation and opportunity, educational attainment, health and survival, political empowerment) and the GCI indicator in OECD countries, with the exception of Japan, Korea, and Iceland. Significant inequalities in health may represent a major obstacle for countries to achieve the required level of competitiveness. These inequalities are a result of differences in health outcomes achieved among various groups of the population, leading to an economic burden in the form of considerable social and economic costs (WHO, 2017). At the same time, socio-economic aspects such as employment status, level of education, income level, place of residence, behavioural and living conditions are key factors in creating these differences (Adler et al., 2016; Balaj et al., 2017; Mackenbach et al., 2019; Omotoso \& Koch, 2018; Oversveen \& Eikemo, 2018).

Differences in health occur in various groups, and can be also seen from different perspectives, for example in terms of colour (Patterson \& Veenstra, 2016) or ethnicity (Allik et al., 2019). From a territorial point of view, it can be stated that the population in Northern and Southern Europe shows better health outcomes than the population in Eastern Europe (Pinillos-Franco \& Somarriba-Arechavala, 2019). Health inequalities are also often discussed in terms of differ- 
ences between men and women (Crimmins et al., 2011; Denton et al., 2004; Heise et al., 2019).

Gender and health inequalities are evident in many health indicators, such as mortality or morbidity (Singh-Manoux et al., 2008). Self-rated health represents a frequently used health indicator, while Roxo \& Perelman (2019) revealed that European women report poorer health than men. Similar results have also been confirmed by many other studies (Caroli \& Weber-Baghdiguian, 2016; Gerritsen \& Deville, 2009; Singh et al., 2013), while Boerma et al. (2016) emphasized that biological and social gender factors can contribute to the creation of such a gender gap. Life expectancy represents another health outcome that makes gender inequalities evident. There is much evidence that men live shorter than women (Barford et al., 2006; Belon et al., 2014; Haeberer et al., 2015; Le et al., 2015). However, the research findings have shown a reduction in gender inequality in life expectancy (Van Oyen et al., 2010). In 1970, the average life expectancy of women was 73 years, in 2015, it increased to 83.2 years. For men, the average life expectancy increased from 66.7 years to 77.9 years, indicating some elimination of differences (Megyesiova \& Lieskovska, 2018). These facts were also confirmed by research studies that deal with gender inequalities in life expectancy and self-rated health, while the findings showed a longer life for Indian women, but their perceptions of health were worse (Bora \& Saikia, 2015).This phenomenon is called the male-female health-survival paradox, which expresses the fact that, despite the poor health status of women, men show a higher level of mortality due to biological, behavioural and social differences between the sexes (Oksuzyan et al., 2010; Van Oyen et al., 2013).

All of the above-mentioned research studies and their findings point to an increase in public awareness and importance in evaluating the effect of health indicators on the economic prosperity of countries. International organizations, as well as research teams in various countries, highlight the importance of eliminating health inequalities between the social, demographic and economic characteristics of the population, which also affect health inequalities in individual countries. The presented study addresses this issue from the perspective of global competitiveness.

\section{RESEARCH OBJECTIVE, METHODOLOGY AND DATA}

The theoretical basis provided evidence on the need to address gender inequalities in health and global competitiveness. A healthy population can be expected to be able to generate competitive economic outputs from which the economy can prosper and compete with other economies. In any case, it should be noted that this issue has been overlooked in the research area. Despite the fact that many studies have confirmed the importance of health and competitiveness, it is still unclear what effect gender inequalities can have on a country's economic life in terms of competitiveness. This was the main impetus for this study to conduct research in this area. Based on the above-mentioned, the main objective of the presented study was to evaluate the effects of selected health indicators on the competitiveness of developed countries.

In order to meet this objective, health and economic data on OECD countries were collected. All of the OECD member countries till the end of 2019 (36 countries) were included in the analyses. Due to the high frequency of missing data from 2019, the latest data from 2018 and the oldest data from 2010 were analysed. Health data were obtained from the OECD databases (OECD, 
2020a), while two main groups were created for the analytical process, namely the life expectancy (LE) group, and the perceived health status (PHS) group. Also, the Global Competitiveness Index (GCI) was used in the analytical processes as economic data from the Global Competitiveness Reports published by the World Economic Forum (WEF, 2020). The period for the GCI (from 2010-2011 to 2018-2019) can be explained by the fact that Global Competitiveness Reports provide year-on-year observation data. The analytical process also included data on the health care system (HCS) as a panel variable. This variable was represented by four categories: a multiple insurance model (MI), a national health system covering the country as a whole (NHS), a regional health system (RHS), and a single payer model (SPM). The countries included in the analyses were classified into the above-mentioned health care systems on the basis of data from the OECD database (OECD, 2016) - (Australia - NHS; Austria - MI; Belgium - MI; Canada - NHS; Chile - MI; Czech Republic - MI; Denmark - NHS; Estonia - SPM; Finland NHS; France - SPM; Germany - MI; Greece - SPM; Hungary - SPM; Iceland - NHS; Ireland - NHS; Israel - MI; Italy - NHS; Japan - MI; Korea - SPM; Latvia - NHS; Lithuania - NHS; Luxembourg - SPM; Mexico - MI; Netherlands - MI; New Zealand - NHS; Norway - NHS; Poland - SPM; Portugal - NHS; Slovak Republic - MI; Slovenia - SPM; Spain - NHS; Sweden RHS; Switzerland - MI; Turkey - SPM; United Kingdom - NHS; United States - MI).

The LE group consisted of four variables (each variable was gender-differentiated): life expectancy at birth (LE_I), life expectancy at the age of 40 years (LE_II), life expectancy at the age of 65 years (LE_III), and life expectancy at the age of 80 (LE_IV). These variables may be defined as the average number of years that a person at that age may be expected to live, assuming that age-specific mortality levels remain constant (OECD, 2020b). The PHS group consisted of three variables (each variable was gender-differentiated): good/very good health (PHS_I), fair (not good, not bad) health (PH_II), and bad/very bad health (PH_III). All these variables included the population over 15 years of age and were expressed as a percentage. Consequently, these variables may be defined as a percentage of the population, aged 15 years old and over, who report their health to be 'good/very good' (or excellent) (all positive response categories), 'fair' (not good, not bad), 'bad/very bad' (all negative response categories) (OECD, 2020c). The competitiveness of countries was represented by the indicator Global Competitiveness Index (GCI), which ranges from 1 to 7 . This range was used in the index methodology until 2017 (inclusive), while from 2018, the range from 0 to 100 is used. These data were standardized to a uniform range, i.e. from 1 to 7 . Based on the theoretical framework, the higher the number, the higher the competitiveness of the country (WEF, 2020).

The analytical research process consisted of the following steps. Firstly, a descriptive analysis and an analysis of differences were applied. The Wilcoxon Rank Sum test, a nonparametric test of the difference between two independent samples, was used to analyse the differences. The Shapiro-Wilk test helped select this particular test based of normality tests. LE and PHS in men, women, as well as inequality (difference) between men and women in absolute value were used in a regression analysis as independent variables. A multiple linear regression analysis (panel model) was used to evaluate the effects of selected health variables on the GCI indicator. Before applying the multiple linear regression, several tests of assumptions were carried out in order to select the most appropriate model. The F Test for Individual and/or Time Effects verified the significance 
of the effect of time series data. The Hausman test was applied to select the correct panel model. Simultaneously, the Bonferroni Outlier Test verified the outliers. Based on the Gauss-Markov theorem, the assumptions of the absence of significant heteroscedasticity and the absence of multicollinearity were primarily tested. The multicollinearity was verified using the Variance Inflation Factors (VIF) method. The homogeneity of variability of residuals (homoscedasticity) was tested using the Breusch-Pagan test. If the assumptions were met, a multiple linear regression model was used. However, if significant heteroscedasticity occurred, the coefficients were estimated using a robust estimator. In conclusion, a correlation analysis was applied using the Spearman's correlation coefficient $\varrho$ that was chosen on the basis of the Royston's multivariate normality test. This analysis was selected in order to assess the relationships between health variables (LE, PHS) and competitiveness. The programming language R v. 3.6.1. (nickname: Action of the Toes) in the R Studio was used in the analyses.

\section{RESULTS AND DISCUSSION}

The analytical processes were conducted in three consecutive parts in order to achieve the objective of the study. The difference analysis together with the descriptive analysis were applied to describe the analysed variables, as well as to show the statistically significant existence of differences (inequalities). Subsequently, the regression analysis was carried out in the second part. Its aim was to evaluate the effects of the LE and PHS indicators on the competitiveness of OECD countries in three separate models for each health variable. Also, the correlation analysis was applied to complete a univariate concept of the relations between health and competitiveness. Table 1 presents the basic outputs of descriptive analysis as well as the results of the normality test using the Shapiro-Wilk test (S-W value, p-value).

Tab. 1 - Health indicators - gender differences. Source: own research

\begin{tabular}{|l|l|l|l|l|l|l|l|l|}
\hline Characteristic & LE_1 & LE_2 & LE_3 & LE_4 & PHS_1 & PHS_2 & PHS_3 \\
\hline Female & Mean & 82.9752 & 43.9006 & 21.0826 & 9.76031 & 65.7378 & 23.4546 & 10.605 \\
\hline & Median & 83.5 & 44.3 & 21.3 & 9.8 & 68.5 & 22.2 & 9.55 \\
\hline & $\begin{array}{l}\text { Std. } \\
\text { Dev. }\end{array}$ & 2.13392 & 1.90238 & 1.44386 & 0.86587 & 14.3161 & 9.98321 & 5.59362 \\
& $\begin{array}{l}\text { S-W } \\
\text { value }\end{array}$ & $0.9444 \dagger$ & $0.9505 \dagger$ & $0.9585 \dagger$ & $0.9648 \dagger$ & $0.9581 \dagger$ & $0.9527 \dagger$ & $0.9602 \dagger$ \\
\hline Male & Mean & 77.4375 & 38.9872 & 17.686 & 7.94781 & 70.1922 & 20.9307 & 8.173 \\
\hline & Median & 78.7 & 40 & 18.2 & 8.1 & 71.85 & 19.3 & 7.8 \\
\hline & $\begin{array}{l}\text { Std. } \\
\text { Dev. }\end{array}$ & 3.35553 & 2.90156 & 1.68168 & 0.84508 & 12.7579 & 9.47395 & 4.03642 \\
\hline & $\begin{array}{l}\text { S-W } \\
\text { value }\end{array}$ & $0.8526 \dagger$ & $0.8557 \dagger$ & $0.8767 \dagger$ & $0.9700 \dagger$ & $0.9492 \dagger$ & $0.9189 \dagger$ & $0.9614 \dagger$ \\
\hline
\end{tabular}

Note: † - p-value < 0.001, S-W - Shapiro-Wilk normality test; Wilcoxon W - Wilcoxon Rank Sum test 
Higher values of life expectancy (LE) were identified in women rather than in men. These results are in accordance with many research findings confirming that women live longer compared to men (Barford et al., 2006; Belon et al., 2014; Haeberer et al., 2015; Le et al., 2015). From the results of another analysed variable representing the self-rated health status on the scale from good to very good (PH_1), it is clear that men perceived their health status more positively than women. This fact was also confirmed by other authors such as Roxo \& Perelman (2019) or Singh et al. (2013). Higher values of fair and negative health status perceived (PH_2 and PH_3) were typical for women, while men reported their health status more positively. Also, these results correspond with other research findings (Caroli \& Weber-Baghdiguian, 2016; Gerritsen \& Deville, 2009). On the other hand, the findings indicate a certain discrepancy; men die at a younger age due to higher morbidity, while women, paradoxically, perceive their health status worse. Bora \& Saikia (2015) revealed similar research findings. In this case, it is possible to discuss the malefemale health-survival paradox, which expresses the fact that despite the poorly perceived health status of women, men achieve a higher level of mortality, and consequently, they live shorter (Van Oyen et al., 2013). Simultaneously, it should be pointed out that life expectancy (LE) in developed countries is considered to be a relatively overall benchmark. However, it is considered to be the most complex benchmark that plays an important role in comparing differences between men and women. The perceived health status can also be considered to be a useful criterion in gender-oriented analyses, which was also confirmed by differences in the real health status and the perceived (self-rated) health status of individuals. In the last lines of Table 1, the results of normality test for men and women are shown. The p-values are lower than 0.05 in all of the cases. Therefore, it is not possible to confirm a significant difference between the distribution of the analysed variables and the normal distribution. The given test verified the difference between the observed values (results for men and women) from zero. It is obvious that the difference was confirmed in all of the cases. In general, the LE variables showed more positive values for women, thus women live longer. On the other hand, the PHS variables showed more positive values for men, thus men perceive their health status more positively. Based on the above-mentioned, it can be concluded that there are health inequalities between men and women, which may be caused by various biological and social gender factors (Boerma et al., 2016). Some research studies confirm the narrowing of these differences (Megyesiova \& Lieskovska, 2018; Van Oyen et al., 2010), but they are still significant in OECD countries.

In the following analytical part of the study, the analyses also include these gender inequalities in health, i.e. the gender differences in LE and PHS in absolute value. Table 2 provides the basic outputs of the descriptive analysis.

Tab. 2 - Gender inequalities in health - descriptive statistics. Source: own research

\begin{tabular}{|l|l|l|l|l|l|l|l|}
\hline $\begin{array}{l}\text { Character- } \\
\text { istic }\end{array}$ & LE_I & LE_II & LE_III & LE_IV & PHS_I & PHS_II & PHS_III \\
\hline Mean & 5.537771 & 4.913438 & 3.396584 & 1.836875 & 4.471429 & 2.633101 & 2.497959 \\
\hline Median & 5.2 & 4.6 & 3.3 & 1.7 & 4.15 & 2.7 & 2.2 \\
\hline Std. Dev. & 1.809961 & 1.646267 & 0.889899 & 0.912959 & 2.790488 & 1.531871 & 1.858803 \\
\hline Min & 2.6 & 1.9 & 1.4 & 0 & 0 & 0 & 0 \\
\hline Max & 11.3 & 9.6 & 5.5 & 4.2 & 11.3 & 7 & 8.5 \\
\hline
\end{tabular}


The study is primarily focused on the average values in interpreting Table 2 . The LE_I variable acquired the value of a significant difference, and based on the values provided in Table 1, higher values can be found in women. Accordingly, it can be assumed that women live 5.7 years longer than men in terms of the average life expectancy. Other analysed variables can be interpreted in a similar way.

Based on the results of the analyses, significant differences in health indicators have been identified between men and women, while health inequalities can play a key role in shaping economic life in countries. This fact was confirmed within other economic dimensions with regard to inequalities among population groups according to race and ethnicity (LaVeist et al., 2011), or among socio-economic groups (Politzer et al., 2019).

Up to this point, only the health dimension of the research objective has been evaluated. The following parts of the study are focused on examining the interconnection of the selected indicators of health and the competitiveness of countries. Firstly, it is important to assess the characteristics of the GCI indicator in order to provide a more detailed picture of the dependent variable.
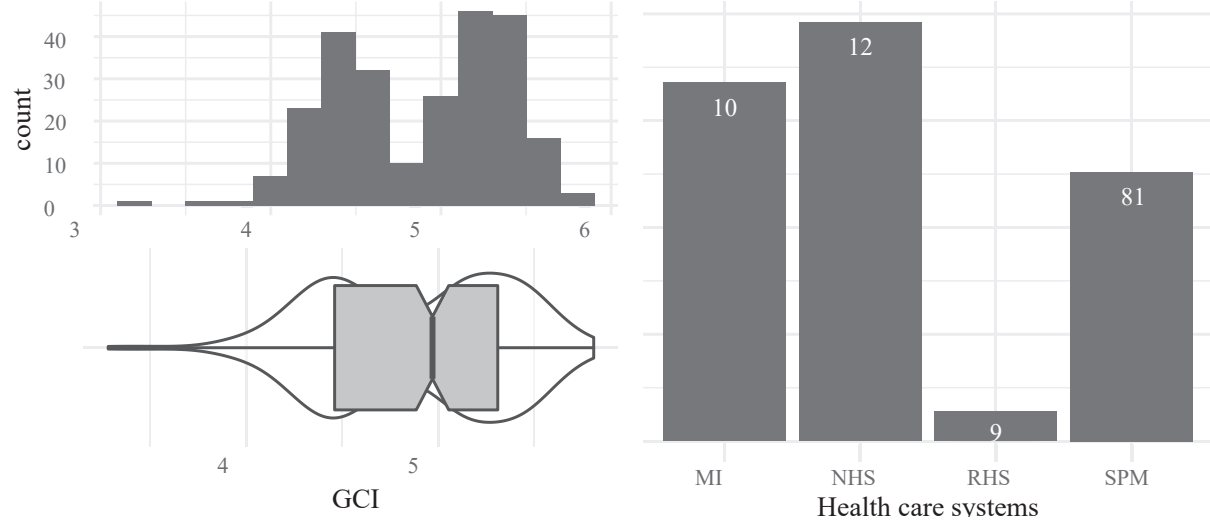

Fig. 1 - Distribution indicators - GCI and HCS. Source: own research

The average value of the GCI indicator during the analysed period was 4.94, while the median value was 5.04. This difference in favour of the higher median value indicates the presence of the outliers shown in Figure 1 (Switzerland values in 2012-2013 and 2013-2014). Standard deviation was 0.50 , skewness was -0.25 and kurtosis was at the level of 0.76 . Figure 1 also shows the absolute frequency of health care systems as a panel variable in panel regression models in the following part of the analyses.

The regression analysis consisted of 6 models, while the specificities of the models were determined by the independent variables. The dependent variable, the GCI indicator, was identical for all models. The first model consisted of the independent variables of LE (LE_I, LE_II, LE_III, LE_IV) in female variant (Model_LE_F). The second model consisted of the independent variables of LE in male variant (Model_LE_M), the third model included the gender inequalities in LE, i.e. the difference between men and women in absolute value (Model_LE_GI). The fourth model contained the independent variables of PHS (PHS_I, PHS_II, PHS_III) in female variant 
(Model_PHS_F), while the fifth model consisted of the independent variables of PHS in male variant (Model_PHS_M). The sixth model included the gender inequalities in PHS, i.e. the difference between men and women in absolute value (Model_PHS_GI). Based on the verification of the effects of years in the individual models using the $F$ test for individual effects, years were not considered to be a variable with a significant effect. The individual countries classified in the health care system variable proved to be significant in all the above-mentioned models; therefore, the application of a panel model was required.

Prior to the application of the regression analysis, it was necessary to verify the assumptions. The Model_LE_F showed questionable values in several variables when verifying the multicollinearity. For this reason, the variables LE_II and LE_III were removed. Subsequently, the VIF value was at the level of 3.38. The Bonferroni test detected two values as significant outliers (Switzerland). Also, the Gauss-Markov theorem suggests that it is appropriate to verify the presence of significant heteroscedasticity. The Hausman test (chisq $=0.39, \mathrm{p}$-value $=0.8222)$ recommended the use of a random effect model, and the Breusch-Pagan test $(\mathrm{BP}=17.53$, $\mathrm{p}$-value $=0.0002)$ confirmed the presence of significant heteroscedasticity; therefore, the White 1 estimator was used to estimate the coefficients.

Tab. 3 - Regression analysis - Model_LE_F. Source: own research

\begin{tabular}{|l|l|l|l|l|l|l|}
\hline $\begin{array}{l}\text { Random } \\
\text { - HC3 } \\
\text { White } 1\end{array}$ & Estimate & CI $2.5 \%$ & CI $97.5 \%$ & Std. Error & z value & $\operatorname{Pr}(>|\mathrm{t}|)$ \\
\hline (Intercept) & -1.8842 & -4.2435 & 0.4750 & 1.2483 & -1.5094 & 0.1312 \\
\hline LE_I & 0.0692 & 0.0330 & 0.1054 & 0.0200 & 3.4689 & 0.0005 \\
\hline LE_IV & 0.1181 & 0.0301 & 0.2060 & 0.0472 & 2.5029 & 0.0123 \\
\hline
\end{tabular}

Note: Multiple R-squared: 0.4437 , Adjusted R-squared: 0.4401

As can be seen in Table 3, the significant coefficients acquired positive values. Based on this, it can be concluded that if life expectancy at birth (LE_I) and at the age of 80 years (LE_IV) in women increases, the competitiveness of countries is also expected to increase.

The second Model_LE_M also showed questionable values in several variables when analysing the multicollinearity. Therefore, the variables LE_II and LE_III were removed. The value of VIF was at the level of 1.06 after this correction. The Bonferroni test identified two significant outliers (Switzerland). The Hausman test $($ chisq $=3.98$, p-value $=0.1372)$ recommended the use of a random effect model, and the Breusch-Pagan test $(\mathrm{BP}=19.239$, $\mathrm{p}$-value $=0.0001)$ confirmed the presence of significant heteroscedasticity. Therefore, even in this case, the White 1 estimator was used to estimate the coefficients. 
Tab. 4 - Regression analysis - Model_LE_M. Source: own research

\begin{tabular}{|l|l|l|l|l|l|l|}
\hline $\begin{array}{l}\text { Random - } \\
\text { HC3 White 1 }\end{array}$ & Estimate & CI 2.5\% & CI 97.5\% & Std. Error & z value & $\operatorname{Pr}(>|\mathrm{t}|)$ \\
\hline (Intercept) & -1.3314 & -2.3091 & -0.3536 & 0.3907 & -3.4077 & 0.0007 \\
\hline LE_I & 0.0774 & 0.0649 & 0.0900 & 0.0050 & 15.5511 & $<0.0001$ \\
\hline LE_IV & 0.0376 & -0.0116 & 0.0868 & 0.0221 & 1.7009 & 0.0890 \\
\hline
\end{tabular}

Note: Multiple R-squared: 0.63 , Adjusted R-squared: 0.6276

Table 4 provides the results of regression analysis in the Model_LE_M. Even in this case, the significant coefficients showed positive values. On this basis, it can be stated that if life expectancy at birth in men (LE_I) increases, an increase in the competitiveness of countries is expected.

The results of the previous two models care consistent with the findings of Onsel et al. (2008) who identified the life expectancy as one of the most important criteria of the competitiveness for the factor-driven economies. Life expectancy, as a potential factor in increasing competitiveness in developing countries, was also used in the study of Salahodjaev \& Nazarov (2013).

In analysing the multicollinearity, the Model LE_GI showed one questionable value in the case of the LE_II variable, and this variable was removed. Subsequently, the VIF value was 5.62 in LE_I, 5.62 in LE_III and 1.47 in LE_4. These outputs were considered acceptable. The Bonferroni test revealed two significant outliers (Switzerland) that were excluded from the analysis. The Hausman test $($ chisq $=6.97, \mathrm{p}$-value $=0.0727)$ recommended the use of a random effect model, and the Breusch-Pagan test $(\mathrm{BP}=0.43$, $\mathrm{p}$-value $=0.9333)$ did not confirm the presence of significant heteroscedasticity.

Tab. 5 - Regression analysis - Model_LE_GI. Source: own research

\begin{tabular}{|l|l|l|l|l|l|l|}
\hline Random & Estimate & CI $2.5 \%$ & CI $97.5 \%$ & Std. Error & z-value & $\operatorname{Pr}(>|\mathrm{t}|)$ \\
\hline (Intercept) & 5.271455 & 5.037147 & 5.505764 & 0.116269 & 45.3384 & $<0.0001$ \\
\hline LE_I & -0.25885 & -0.31239 & -0.2053 & 0.023916 & -10.8234 & $<0.0001$ \\
\hline LE_III & 0.333313 & 0.225104 & 0.441522 & 0.046872 & 7.1111 & $<0.0001$ \\
\hline LE_IV & 0.000674 & -0.05466 & 0.056011 & 0.024578 & 0.0274 & 0.9809 \\
\hline
\end{tabular}

Note: Multiple R-squared: 0.6106, Adjusted R-squared: 0.6068

Based on the results in Table 5, a negative coefficient can be found in the LE_I variable. Therefore, a reduction in gender inequalities in life expectancy at birth can lead to increased competitiveness. The opposite situation can be seen in the case of LE_III with a positive coefficient, which indicates that if gender inequality in life expectancy at the age of 65 years increases, countries' competitiveness is also expected to increase. In general, men who live longer may offer their competitive advantage in the economy. On the other hand, the population group covered by the life expectancy at the age of 65 years is represented by economically unproductive people with higher social and health costs. Therefore, if the gender inequality increases, it will mean greater differences in this group limited by age, indicating higher mortality on one side of the sex, and accordingly, lower costs in countries. This fact may be reflected in the economic condition of countries. Also, it is important to emphasize that the LE_I coefficient is more significant for the competitiveness index 
than LE_III, suggesting that life expectancy at birth is a very important health indicator in the examined problem.

The above-mentioned findings reveal not only that reducing gender inequalities in life expectancy at birth can lead to greater competitiveness, but also that there is a need to focus on men in this effort, as this gender group showed a higher significance of the effect on competitiveness compared to women. In other words, increasing the average life expectancy at birth in the case of men will reduce gender inequality with a greater effect on competitiveness.

In analysing the multicollinearity, the Model_PHS_F showed a questionable value in the PHS_I variable that was removed. The VIF value was at the level of 3.41 in other two independent variables (PHS_II and PHS_III). The Bonferroni test revealed two significant outliers (Switzerland) and these values were removed from the analysis. The Hausman test $(\mathrm{chisq}=4.47, \mathrm{p}$-value $=0.1073)$ recommended the use of a random effect model, and the Breusch-Pagan test $(\mathrm{BP}=22.02$, $\mathrm{p}$-value $<0.0001)$ confirmed the presence of significant heteroscedasticity; therefore, the White 1 estimator was used to estimate the coefficients.

Tab. 6 - Regression analysis - Model_PHS_F. Source: own research

\begin{tabular}{|l|l|l|l|l|l|l|}
\hline $\begin{array}{l}\text { Random - } \\
\text { HC3 White 1 }\end{array}$ & Estimate & CI 2.5\% & CI 97.5\% & Std. Error & z value & $\operatorname{Pr}(>|\mathrm{t}|)$ \\
\hline (Intercept) & 5.1590 & 5.0040 & 5.3139 & 0.0982 & 52.5322 & $<0.0001$ \\
\hline PHS_II & 0.0340 & 0.0264 & 0.0417 & 0.0053 & 6.3962 & $<0.0001$ \\
\hline PHS_III & -0.0956 & -0.1101 & -0.0811 & 0.0086 & -11.0595 & $<0.0001$ \\
\hline
\end{tabular}

Note: Multiple R-squared: 0.6736, Adjusted R-squared: 0.6713

The results in Table 6 point to the fact that if the proportion of women who report a fair perception of their health status (PHS_II) increases, the competitiveness of countries is also expected to increase. On the other hand, a decrease in the proportion of women who report a negative perception of their health status (PHS_III) may lead to an increase in the competitiveness of countries.

When verifying the multicollinearity, the Model_PHS_M showed a questionable value in the PHS_I variable, which was removed. The VIF value was at the level of 3.08 in other two independent variables (PHS_II and PHS_III). The Bonferroni test detected two significant outliers (Switzerland) that were also excluded from the analysis. The Hausman test (chisq $=2.05, \mathrm{p}$-value $=$ 0.3579) recommended the use of a random effect model, and the Breusch-Pagan test (BP $=31.86$, p-value $<0.0001)$ confirmed the presence of significant heteroscedasticity. Accordingly, the White 1 estimator was used to estimate the coefficients.

Tab. 7 - Regression analysis - Model_PHS_M. Source: own research

\begin{tabular}{|l|l|l|l|l|l|l|}
\hline $\begin{array}{l}\text { Random - } \\
\text { HC3 White 1 }\end{array}$ & Estimate & CI 2.5\% & CI 97.5\% & Std. Error & z value & $\operatorname{Pr}(>|\mathrm{t}|)$ \\
\hline (Intercept) & 5.2369 & 5.0782 & 5.3956 & 0.0999 & 52.4044 & $<0.0001$ \\
\hline PHS_II & 0.0347 & 0.0266 & 0.0428 & 0.0046 & 7.5205 & $<0.0001$ \\
\hline PHS_III & -0.1249 & -0.1456 & -0.1043 & 0.0111 & -11.2074 & $<0.0001$ \\
\hline
\end{tabular}

Note: Multiple R-squared: 0.6479, Adjusted R-squared: 0.6454 
The results in Table 7 point to the fact that if the proportion of men who report a fair perception of their health status increases (PHS_II), the competitiveness of countries is also expected to increase. On the other hand, a decrease in the proportion of men who report a negative perception of their health status (PHS_III) may lead to an increase in the competitiveness of countries. Overall, a higher rate of outputs' significance was measured in the case of men.

When verifying the multicollinearity, the Model_PHS_GI also showed one questionable value in the PHS_I variable that was removed. The VIF value was 1.10 for the other two independent variables (PHS_II and PHS_III). The Bonferroni test revealed two significant outliers (Switzerland) and these values were removed from the analysis. The Hausman test ( $\mathrm{chisq}=29.58$, p-value $<$ 0.0001) recommended the use of a fixed effect model, and the Breusch-Pagan test (BP $=13.189$, p-value $<0.0014)$ confirmed the presence of significant heteroscedasticity. Therefore, in this case, the Arellano estimator was used to estimate the coefficients.

Tab. 8. - Regression analysis - Model_PHS_GI. Source: own research

\begin{tabular}{|l|l|l|l|l|l|l|}
\hline $\begin{array}{l}\text { Fixed - HC3 } \\
\text { Arellano }\end{array}$ & Estimate & CI 2.5\% & CI 97.5\% & Std. Error & t value & $\operatorname{Pr}(>|\mathrm{t}|)$ \\
\hline PHS_II & -0.10032 & -0.1297 & -0.0710 & 0.0241 & -4.1615 & $<0.0001$ \\
\hline PHS_III & -0.10653 & -0.1306 & -0.0824 & 0.0315 & -3.3860 & 0.0008 \\
\hline
\end{tabular}

Note: Multiple R-squared: 0.3939, Adjusted R-squared: 0.3831

From the results in Table 8 , it is evident that if the gender inequality in perceived health status decreases, the competitiveness of countries is expected to increase. The above-mentioned findings confirm the general considerations that a reduction in health inequalities in the economy brings economic benefits (Nanney et al., 2019). Also, this fact can be confirmed in terms of gender inequalities in perceived health status (PHS), indicating if a gender gap narrows and the population perceives its own health more positive, the competitive advantage in various economic areas will increase. People feel healthier, physically and emotionally stronger, tougher, as well as more productive (Doan et al., 2020; WHO, 2002). The results confirm this interconnection from the perspective of competitiveness.

The previous regression analysis provides a multivariate view of the relations between selected health and economic outputs. Table 9 shows the results of the correlation analysis that offers a univariate view and it includes all independent variables. The primary assumption for selecting an appropriate test was a normality verified by the Royston's multivariate normality test, which did not show a p-value higher than 0.05 in none of the analysed cases. It means that the assumption of normality was not met. The Spearman's nonparametric $\varrho$ coefficient was considered the appropriate.

Tab. 9 - Correlation analysis (Spearman's correlation coefficient @). Source: own research

\begin{tabular}{|l|l|l|l|l|l|l|l|}
\hline GCI x Health & LE_I & LE_II & LE_III & LE_IV & PHS_I & PHS_II & PHS_III \\
\hline Female & $0.37 \dagger$ & $0.38 \dagger$ & $0.39 \dagger$ & $0.43 \dagger$ & $0.50 \dagger$ & $-0.31 \dagger$ & $-0.54 \dagger$ \\
\hline Male & $0.53 \dagger$ & $0.55 \dagger$ & $0.51 \dagger$ & $0.26 \dagger$ & $0.41 \dagger$ & $-0.25 \dagger$ & $-0.48 \dagger$ \\
\hline Gender Inequal. & $-0.55 \dagger$ & $-0.48 \dagger$ & $-0.34 \dagger$ & $0.17 * * *$ & $-0.62 \dagger$ & $-0.44 \dagger$ & $-0.62 \dagger$ \\
\hline
\end{tabular}

Note: $* * *$ - p-value $<0.01 ; \dagger$ - p-value $<0.001$ 
The results in Table 9 may be divided into three parts. The first line shows the output of the correlation coefficient $\varrho$, while the second line shows the $\mathrm{p}$-value. However, it is important to state that all tested relations appeared to be significant. As for gender inequalities in health, all outputs of the correlation coefficients are negative, which is a positive output for the competitiveness of countries. This suggests that increasing competitiveness may be associated with reducing gender inequalities in health. When comparing the outputs of men and women, the variables LE_I, LE_II and LE_III show higher values of the coefficients for men. Women were dominant in the LE_IV variable. It can be stated that the activities which increase life expectancy could be more effective in the case of men than women in terms of increasing the competitiveness of countries. The correlation analysis also revealed a significant relationship between the competitiveness of countries and the positive perception of health status. This relationship was stronger in the case of women than men; however, these differences were not significant.

The overall results indicate that the health of the population, as well as the gender inequalities in health, are key factors that can affect the competitive position of countries around the world. Accordingly, it is important to emphasize that the countries should focus on health of their own residents, as well as on reducing the gender inequalities in health, in order to increase their own competitiveness. The above-mentioned facts provide space for active health and social policymaking. This study revealed the fact that public policies should focus on increasing the life expectancy of productive population as well as improving the self-rated health status of individuals. This can be achieved through an improved health and social system in a country. Also, the financing of health care plays an important role in this effort, as health expenditure is positively associated with population longevity (Bein et al., 2017) and social support (Reynolds \& Avendano, 2018). Last but not least, other evidence showed that increased health expenditure can lead to a reduction in longevity inequalities (Obrizan \& Wehby, 2018). Another recommendation for policy makers, based on the findings, is health prevention and education, which should be promoted among the population. A healthy lifestyle is considered to be a key determinant of population longevity (Li et al., 2018) and health perceptions (Marques et al., 2019), while unhealthy and risky behaviour (such as smoking, poor diet, alcohol consumption and physical inactivity) may result in reduced health, life expectancy (Mehta \& Myrskyla, 2017), as well as self-rated health status (Chan et al., 2015). Efforts to support the social and health systems, prevention and education, would be transformed into economic life, the competitiveness of countries in particular.

\section{CONCLUSION}

Population health has an effect on a number of economic aspects, while each of these economic areas creates a picture of competitiveness among the individual countries. However, the relation between the population health and the competitiveness of the countries in which these people live requires broader research. The main reason is especially the methodological difficulty of the research process, as well as the absence of research trajectories that would have an implicational character for relevant types of policies. Also, it is important to choose relevant variables wisely as the main representatives of the population health that would accurately quantify the effect and dependence of health and economic categories. The main objective of the presented study was to evaluate the effects of selected health indicators on the competitiveness of developed countries. 
This objective was achieved through various analyses and their main findings are summarized in the following text.

The results of the analysis of differences showed significant gender differences in all analysed health variables, while life expectancy showed considerable values indicating the well-known fact that women live longer than men. As expected, the differences in perceived health status revealed positive results for men. The regression analysis provided very interesting results that have added value, especially when comparing them with each other. The effect of life expectancy at birth was considered to be very significant for the competitiveness of economies, in terms of male outputs, female outputs, as well as outputs of gender inequality. Similarly, a relatively strong effect on competitiveness was also found in the perceived health status. These results were also confirmed by the correlation analysis that revealed significant negative coefficients in almost all of the relations between competitiveness and gender inequalities in health indicators. Based on these all findings, it can be concluded that a reduction in gender inequalities can lead to an increase in the competitiveness of countries. In any case, this study confirms economic theories that consider health to be an important economic factor.

Potential limitation of this study may be a fact that data from the OECD database were not entirely used. The main reason was the assumption that the larger timeline, the higher chance that the given data will be influenced by various economic, social, and other effects (shocks). The sample is considered sufficient, and consequently, relevant results may be presented. In future research, it is planned to link the examined variables with education and other socio-economic indicators. Future research will also include various geographical aspects, and their link to healthcare accessibility and healthcare costs will offer further insight into this issue.

\section{Acknowledgments}

This research was funded by the Slovak Research and Development Agency under the contract No. APVV-170360: "Multidimensional analysis of significant determinants of public procurement efficiency with emphasis on the application of Health Technology Assessment in the procurement preparation phase".

\section{References}

1. Adler, N. E., Glymour, M. M., \& Fielding, J. (2016). Addressing social determinants of health and health inequalities. JAMA-Journal of the American Medical Association, 316(16), 1641-1642. http://dx.doi.org/10.1001/jama.2016.14058

2. Allik, M., Brown, D., Dundas, R., \& Leyland, A.H. (2019). Differences in ill health and in socioeconomic inequalities in health by ethnic groups: a cross-sectional study using 2011 Scottish census. Ethnicity \& Health. http://dx.doi.org/10.1080/13557858.2019.1643009

3. Balaj, M., McNamara, C. L., Eikemo, T. A., \& Bambra, C. (2017). The social determinants of inequalities in self-reported health in Europe: findings from the European social survey (2014) special module on the social determinants of health. European Journal of Public Health, 27, 107-114. http://dx.doi.org/10.1093/eurpub/ckw217

4. Bar, M., \& Leukhina, O. (2010). The role of mortality in the transmission of knowledge. Journal of Economic Growth, 15(4), 291-321. http://dx.doi.org/10.1007/s10887-010-9059-5

5. Barford, A., Dorling, D., Smith, G. D., \& Shaw, M. (2006). Life expectancy: women now on top everywhere - During 2006, even in the poorest countries, women can expect to outlive men. BMJ-British Medical Journal, 332(7545), 808-808. http://dx.doi.org/10.1136/bmj.332.7545.808 
6. Bein, M.A., Unlucan, D., Olowu, G., \& Kalifa, W. (2017). Healthcare spending and health outcomes: evidence from selected East African countries. African Health Sciences, 17(1), 247-254. http://dx.doi.org/10.4314/ahs.v17i1.30

7. Belon, A. P., Lima, M. G., \& Barros, M. B. A. (2014). Gender differences in healthy life expectancy among Brazilian elderly. Health and Quality of Life Outcomes, 12, 88. http://dx.doi. org/10.1186/1477-7525

8. Birader, T.G., Öztüren, A. (2019). Motivators and Perceptions of Island Residents towards Medical Tourism in Mainland. Journal of Tourism and Services, 10(19), 164-176. https://doi. org/10.29036/jots.v10i19.99

9. Bloom, D. E., Canning, D., \& Sevilla, J. (2004). The effect of health on economic growth: a production function approach. World Development, 32(1), 1-13. http://dx.doi.org/10.1016/j. worlddev.2003.07.002

10. Bloom, D., \& Canning, D. (2003). Health as human capital and its impact on economic performance. Geneva Papers on Risk and Insurance-Issues and Practice, 28(2), 304-315. http://dx.doi. org/10.1111/1468-0440.00225

11. Boerma, T., Hosseinpoor, A. R., Verdes, E., \& Chatterji, S. (2016). A global assessment of the gender gap in self-reported health with survey data from 59 countries. BMC Public Health, 16, 675. http://dx.doi.org/10.1186/s12889-016-3352-y

12. Bora, J. K., \& Saikia N. (2015). Gender differentials in self-rated health and self-reported disability among adults in India. Plos One, 10(11), e0141953.http://dx.doi.org/10.1371/journal. pone. 0141953

13. Bucher, S. (2018). The Global Competitiveness Index as an indicator of sustainable development. Herald of the Russian Academy of Sciences, 88(1), 44-57. http://dx.doi.org/10.1134/ S1019331618010082

14. Caroli, E., \& Weber-Baghdiguian, L. (2016) Self-reported health and gender: the role of social norms. Social Science \& Medicine, 153, 220-229. http://dx.doi.org/10.1016/j. socscimed.2016.02.023

15. Chan, Y. Y., Teh, C. H., Lim, K. K., Lim, K. H., Yeo, P. S., Kee, C. C., Omar, M. A., \& Ahmad, N. A. (2015). Lifestyle, chronic diseases and self-rated health among Malaysian adults: results from the 2011 National Health and Morbidity Survey (NHMS). BMC Public Health, 15, 754. http://dx.doi.org/10.1186/s12889-015-2080-z

16. Crimmins, E. M., Kim, J. K., \& Sole-Auro A. (2011). Gender differences in health: results from SHARE, ELSA and HRS. European Journal of Public Health, 21(1), 81-91. http://dx.doi. org/10.1093/eurpub/ckq022

17. Denton, M., Prus, S., \& Walters, V. (2004). Gender differences in health: a Canadian study of the psychosocial, structural and behavioural determinants of health. Social Science \& Medicine, 58(12), 2585-2600. http://dx.doi.org/10.1016/j.socscimed.2003.09.008

18. Doan, T., Strazdins, L., \& Leach, L. (2020). Cost of poor health to the labour market returns to education in Australia: another pathway for socio-economic inequality. European Journal of Health Economics, 21(4), 635-648. http://dx.doi.org/10.1007/s10198-020-01163-2 
19. French, D. (2012). Causation between health and income: a need to panic. Empirical Economics, 42(2), 582-601. http://dx.doi.org/10.1007/s00181-011-0541-5

20. Gehringer, A., \& Prettner, K. (2019). Longevity and technological change. Macroeconomic Dynamics, 23(4), 1471-1503. http://dx.doi.org/10.1017/S1365100517000293

21. Gerritsen, A. A. M., \& Deville, W. L. (2009). Gender differences in health and health care utilisation in various ethnic groups in the Netherlands: a cross-sectional study. BMC Public Health, 9, 109. http://dx.doi.org/10.1186/1471-2458-9-109

22. Haeberer, M., Noguer, I., \& Mujica, O. J. (2015). Educational inequalities in mortality and survival of women and men in the Americas, 1990-2010. Revista Panamericana de Salud PublicaPan American Journal of Public Health, 38(2), 89-95.

23. Heise, L., Greene, M. E., Opper, N., Stavropoulou, M., Harper, C., Nascimento, M., Zewdie, D., Darmstadt, G., Greene, M., Hawkes, S., Heise, L., Henry, S., Heymann, J., Klugman, J., Levine, R., Raj, A., \& Gupta, G. R. (2019). Gender inequality and restrictive gender norms: framing the challenges to health. Lancet, 393(10189), 2440-2454. http://dx.doi.org/10.1016/ S0140-6736(19)30652-X

24. Hena, S., Luan, J., \& Zhang, O. (2019). Human capital in the manufacturing sector from 1972 to 2015 and its association with economic growth of Pakistan. International Journal of Advanced and Applied Sciences, 6(6), 43-50. http://dx.doi.org/10.21833/ijaas.2019.06.007

25. Herzer, D. (2020). How does mortality affect innovative activity in the long run? World Development, 125, 104688. http://dx.doi.org/10.1016/j.worlddev.2019.104688

26. Herzer, D., \& Nagel, K. (2019). The impact of adult and non-adult mortality on development: two centuries evidence from a panel of industrial countries. Journal of Policy Modeling, 41(2), 352-371. http://dx.doi.org/10.1016/j.jpolmod.2019.02.008

27. Jiang, J., Huang, W., Wang, Z., \& Zhang, G. (2019). The effect of health on labour supply of rural elderly people in China-a An empirical analysis using CHARLS data. International Journal of Environmental Research and Public Health, 16(7), 1195. http://dx.doi.org/10.3390/ijerph16071195

28. Kalemli-Ozcan, S., Ryder, H. E., \& Weil, D. N. (2000). Mortality decline, human capital investment, and economic growth. Journal of Development Economics, 62(1), 1-23. http://dx.doi. org/10.1016/S0304-3878(00)00073-0

29. Khan, H. N., Razali, R. B., \& Shafei, A. B. (2016). On the relationship between health, education and economic growth: time series evidence from Malaysia. Proceeding of the 4th International Conference of Fundamental and Applied Sciences 2016 (ICFAS2016), 1787, 080007. http://dx.doi.org/10.1063/1.4968146

30. Kim, Y. (2018). Eliminating poverty in the 21st century the role of health and human capital. JAMA-Journal of the American Medical Association, 320(14), 1427-1428. http://dx.doi. org/10.1001/jama.2018.13709

31. Kroupova, Z. K., \& Rezankova, H. (2016). Relationship of gender gap, competitiveness and sustainability of economy - position of the Czech Republic in international comparison. Politicka Ekonomie, 64(4), 468-491. http://dx.doi.org/10.18267/j.polek.1083

32. Lall, S. (2001). Competitiveness indices and developing countries: an economic evaluation of the Global Competitiveness Report. World Development, 29(9), 1501-1525. http://dx.doi. org/10.1016/S0305-750X(01)00051-1 
33. LaVeist, T. A., Gaskin, D., \& Richard, P. (2011). Estimating the economic burden of racial health inequalities in the United States. International Journal of Health Services, 41(2), 231-238. http://dx.doi.org/10.2190/HS.41.2.c

34. Le, Y., Ren, J., Shen, J., Li, T., \& Zhang, C. (2015). The changing gender differences in life expectancy in Chinese cities 2005-2010. Plos One, 10(4), e0123320. http://dx.doi.org/10.1371/ journal.pone. 0123320

35. Lechman, E. (2019). Still 'few, slow and low'? On the female dimension of technology, labour markets and economic activity: evidence for the period of 1990-2017. Economics and Sociology, 12 (1), 11-38. https://doi.org/10.14254/2071-789X.2019/12-1/1

36. Li, H., \& Huang, L. (2009). Health, education, and economic growth in china: empirical findings and implications. China Economic Review, 20(3), 374-387. http://dx.doi.org/10.1016/j. chieco.2008.05.001

37. Li, Y., Pan, A., Wang, D. D., Liu, X., Dhana, K., Franco, O. H., Kaptoge, S., Di Angelantonio, E., Stampfer, M., Willett, W. C., \& Hu, F. B. (2018). Impact of healthy lifestyle factors on life expectancies in the US population. Circulation, 138(4), 345-355. http://dx.doi.org/10.1161/ CIRCULATIONAHA.117.032047

38. Mackenbach, J. P., Valverde, J. R., Bopp, M., Bronnum-Hansen, H., Deboosere, P., Kalediene, R., Kovacs, K., Leinsalu, M., Martikainen, P., Menvielle, G., Regidor, E., \& Nusselder, W. J. (2019). Determinants of inequalities in life expectancy: an international comparative study of eight risk factors. Lancet Public Health, 4(10), 529-537. http://dx.doi.org/10.1016/S24682667(19)30147-1

39. Madsen, J. B. (2016). Health, human capital formation and knowledge production: two centuries of international evidence. Macroeconomic Dynamics, 20(4), 909-953. http://dx.doi. org $/ 10.1017 / \mathrm{S} 1365100514000650$

40. Marques, A., Peralta, M., Santos, T., Martins, J., \& de Matos, M. G. (2019). Self-rated health and health-related quality of life are related with adolescents' healthy lifestyle. Public Health, 170, 89-94. http://dx.doi.org/10.1016/j.puhe.2019.02.022

41. Megyesiova, S., \& Lieskovska, V. (2018). Analysis of the sustainable development indicators in the OECD countries. Sustainability, 10(12), 4554. http://dx.doi.org/10.3390/su10124554

42. Mehta, N., \& Myrskyla, M. (2017). The population health benefits of a healthy lifestyle: life expectancy increased and onset of disability delayed. Health Affairs, 36(8), 1495-1502. http:// dx.doi.org/10.1377/hlthaff.2016.1569

43. Mihalache, I. C. (2019). Health state of human capital in the economic theory. Postmodern Openings, 10(4), 182-192. http://dx.doi.org/10.18662/po/102.

44. Monterubbianesi, P. D., Granes, M., \& Dabus, C. (2017). New evidence of the health status and economic growth relationship. Panoeconomicus, 64(4), 439-459. http://dx.doi.org/10.2298/ PAN150505020M

45. Nanney, M. S., Myers, S. L., Xu, M., Kent, K., Durfee, T., \& Allen, M. L. (2019). The economic benefits of reducing racial disparities in health: the case of Minnesota. International Journal of Environmental Research and Public Health, 16(5), 742. http://dx.doi.org/10.3390/ijerph16050742 
46. Nemec, J., Kubak, M., Krapek, M., \& Horehajova, M. (2020). Competition in Public Procurement in the Czech and Slovak Public Health Care Sectors. Healthcare, 8, 201.

47. Obrizan, M., \& Wehby, G. L. (2018). Health expenditures and global inequalities in longevity. World Development, 101, 28-36. http://dx.doi.org/10.1016/j.worlddev.2017.08.003

48. OECD. (2016). Health Systems Characteristics Survey. 2016. Retrieved February 9, 2020 from http://www.oecd.org/els/health-systems/OECD-HSC-Survey-2016-Project-outline.pdf

49. OECD. (2019). Health for Everyone? Social Inequalities in Health and Health Systems. OECD Health Policy Studies. OECD Publishing: Paris, France, 2019. http://dx.doi.org/10.1787/3c8385d0-en

50. OECDa. (2020a). OECD.stat. Retrieved January 1, 2020 from https://stats.oecd.org/\#

51. OECDb. (2020b). Live Expectancy. Retrieved January 2, 2020 from https://stats.oecd.org/ wbos/fileview2.aspx?IDFile=67212df7-883f-42ca-b389-9cb6500545f3

52. Oksuzyan, A., Bronnum-Hansen, H., \& Jeune, B. (2010). Gender gap in health expectancy. European Journal of Ageing, 7(4), 213-218. http://dx.doi.org/10.1007/s10433-010-0170-4

53. Omotoso, K. O., \& Koch, S. F. (2018). Assessing changes in social determinants of health inequalities in South Africa: a decomposition analysis. International Journal for Equity in Health, 17, 181. http://dx.doi.org/10.1186/s12939-018-0885-y

54. Onsel, S., Ulengin, F., Ulusoy, G., Aktas, E., Kabak, O., \& Topcu, Y. I. (2008). A new perspective on the competitiveness of nations. Socio-Economic Planning Sciences, 42, 221-246. http:// dx.doi.org/10.1016/j.seps.2007.11.001

55. Oversveen, E., \& Eikemo, T. A. (2018). Reducing social inequalities in health: moving from the 'causes of the causes' to the 'causes of the structures'Special issue: social inequalities in health and their determinants. Scandinavian Journal of Public Health, 46(1), 1-5. http://dx.doi. org $/ 10.1177 / 1403494818756574$

56. Pacáková, V., \& Kopecká, L. (2018). Comparing inequalities in health outcomes in European countries. Journal of International Studies, 11(4), 215-227. https://doi.org/10.14254/2071$8330.2018 / 11-4 / 15$

57. Patterson, A. C., \& Veenstra, G. (2016). Black-White health inequalities in Canada at the intersection of gender and immigration. Canadian Journal of Public Health-Revue Canadienne de Sante Publique, 107(3), 278-284. http://dx.doi.org/10.17269/CJPH.107.5336http://dx.doi.org/10.17269/ CJPH.107.5336

58. Pinillos-Franco, S., \& Somarriba-Arechavala, N. (2019). A proposal for a synthetic health indicator in the European Union: an analysis of gender health inequalities. Applied Research in Quality of Life, 14(4), 1019-1033. http://dx.doi.org/10.1007/s11482-018-9637-9

59. Politzer, E., Shmueli, A., \& Avni S. (2019). The economic burden of health disparities related to socioeconomic status in Israel. Israel Journal of Health Policy Research, 8, 46. http://dx.doi. org/10.1186/s13584-019-0306-8

60. Rakauskienè, O. G., Volodzkienè, L. (2017), The inequality of material living conditions in EU countries. Economics and Sociology, 10(1), 265-278. https://doi.org/http://dx.doi. org/10.14254/2071-789X.2017/10-1/19 
61. Reynolds, M. M., \& Avendano, M. (2018). Social policy expenditures and life expectancy in high-income countries. American Journal of Preventive Medicine, 54(1), 72-79. http://dx.doi. org/10.1016/j.amepre.2017.09.001

62. Roxo, L., \& Perelman, J. (2019). Gender inequality in self-reported health and its evolution in Europe between 2004 and 2016. European Journal of Public Health, 29(4). http://dx.doi. org/10.1093/eurpub/ckz185.005

63. Salahodjaev, R., \& Nazarov, Z. (2013). An econometric approach of computing competitiveness index in human capital. Journal of Applied Economics and Business Research, 3(1), $51-64$

64. Sharma, R. (2018). Health and economic growth: evidence from dynamic panel data of 143 years. Plos One, 13(10), e0204940. http://dx.doi.org/10.1371/journal.pone.0204940

65. Singh, L., Arokiasamy, P., Singh, P. K., \& Rai, R. K. (2013). Determinants of gender differences in self-rated health among older population: evidence from India. SAGE Open, 3(2), 2158244013487914. http://dx.doi.org/10.1177/2158244013487914

66. Singh-Manoux, A., Gueguen, A., Ferrie, J., Shipley, M., Martikainen, P., Bonenfant, S., Goldberg, M., \& Marmot, M. (2008). Gender differences in the association between morbidity and mortality among middle-aged men and women. American Journal of Public Health, 98(12), 2251-2257. http://dx.doi.org/10.2105/AJPH.2006.107912

67. Štefko, R., Jenčová, S. \& Vašaničová, P. (2020). The Slovak Spa Industry and Spa Companies: Financial and Economic Situation. Journal of Tourism and Services, 20(11), 28-43. https://doi. org/10.29036/jots.v11i20.137

68. Šumpíková, M., \& Durčeková, I. (2019). Transaction Costs, Outsourcing, and the Public Procurement Review Process in the Czech Republic and Slovakia. NISPAcee Journal of Public Administration and Policy, 12(2), 233-250. https://doi.org/10.2478/nispa-2019-0021

69. Van Oyen, H., Cox, B., Jagger, C., Cambois, E., Nusselder, W., Gilles, C., \& Robine, J. M. (2010). Gender gaps in life expectancy and expected years with activity limitations at age 50 in the European Union: associations with macro-level structural indicators. European Journal of Ageing, 7(4), 229-237. http://dx.doi.org/10.1007/s10433-010-0172-2

70. Van Oyen, H., Nusselder, W., Jagger, C., Kolip, P., Cambois, E., \& Robine, J. M. (2013). Gender differences in healthy life years within the EU: an exploration of the "health-survival" paradox. International Journal of Public Health, 58(1), 143-155. http://dx.doi.org/10.1007/s00038012-0361-1

71. WEF. (2020). Global Competitiveness Report. Retrieved August 6, 2020, from http://reports. weforum.org

72. Weil, D. N. (2007). Accounting for the effect of health on economic growth. Quarterly Journal of Economics, 122(3), 1265-1306. http://dx.doi.org/10.1162/qjec.122.3.1265

73. WHO. (2002). Health, Economic Growth, and Poverty Reduction. The Report of Working Group 1 of the Commission on Macroeconomics and Health. Geneva: World Health Organization. Retrieved February 9, 2020, from https:/apps.who.int/iris/bitstream/ handle/10665/42492/9241590092.pdf;jsessionid=19B0494A7B879D7BE2F98CC714DFCFC5 ?sequence $=1$ 
74. WHO. (2013). Health 2020: a European policy framework supporting action across government and society for health and well-being. WHO Regional Office for Europe. Retrieved August 6, 2020, from http://www.euro.who.int/__data/assets/pdf_ file/0006/199536/Health2020-Short.pdf?ua=1

75. WHO. (2017). 10 facts on health inequities and their causes. Retrieved February 9, 2020, from https://www.who.int/features/factfiles/health_inequities/en/

\section{Contact information}

prof. Ing. Beata Gavurova, PhD., $M B A$

Technical University of Kosice

Faculty of Mining, Ecology, Process Control and Geotechnologies

Institute of Earth Resources

Slovakia

E-mail:beata.gavurova@tuke.sk

ORCID: 0000-0002-0606-879X

Mgr. Viera Ivankova

University of Presov

Faculty of Management

Department of Economics and Economy

Slovakia

E-mail:viera.ivankova@smail.unipo.sk

ORCID:0000-0002-6164-1165

Mgr. Martin Rigelsky

University of Presov

Faculty of Management

Department of Marketing and International Trade

Slovakia

E-mail:martin.rigelsky@smail.unipo.sk

ORCID: 0000-0003-1427-4689

Ing. Iveta Kmecova, $\mathrm{PhD}$.

Institute of Technology and Business

Faculty of Corporate Strategy

Czech Republic

e-mail:kmecova@mail.vstecb.cz.

ORCID: 0000-0002-0406-2861 